\title{
Mandenkan
}

MANDENIKAN Bulletin semestriel d'études linguistiques mandé

$50 \mid 2013$

Numéro 50

\section{Le Mandenkan de Gérard Dumestre}

\section{Valentin Vydrin}

\section{(2) OpenEdition}

Journals

Édition électronique

URL : https://journals.openedition.org/mandenkan/197

DOI : 10.4000/mandenkan. 197

ISSN : 2104-371X

Éditeur

Llacan UMR 8135 CNRS/Inalco

Édition imprimée

Date de publication : 1 décembre 2013

Pagination : 2

ISSN : 0752-5443

\section{Référence électronique}

Valentin Vydrin, "Le Mandenkan de Gérard Dumestre », Mandenkan [En ligne], 50 | 2013, mis en ligne le 01 décembre 2013, consulté le 08 juillet 2021. URL : http://journals.openedition.org/mandenkan/197 ; DOI : https://doi.org/10.4000/mandenkan. 197

Ce document a été généré automatiquement le 8 juillet 2021.

\section{c) (i) (2)}

Les contenus de Mandenkan sont mis à disposition selon les termes de la Licence Creative Commons Attribution - Pas d'Utilisation Commerciale - Partage dans les Mêmes Conditions 4.0 International. 


\section{Le Mandenkan de Gérard Dumestre}

\section{Valentin Vydrin}

\section{Gérard Dumestre}

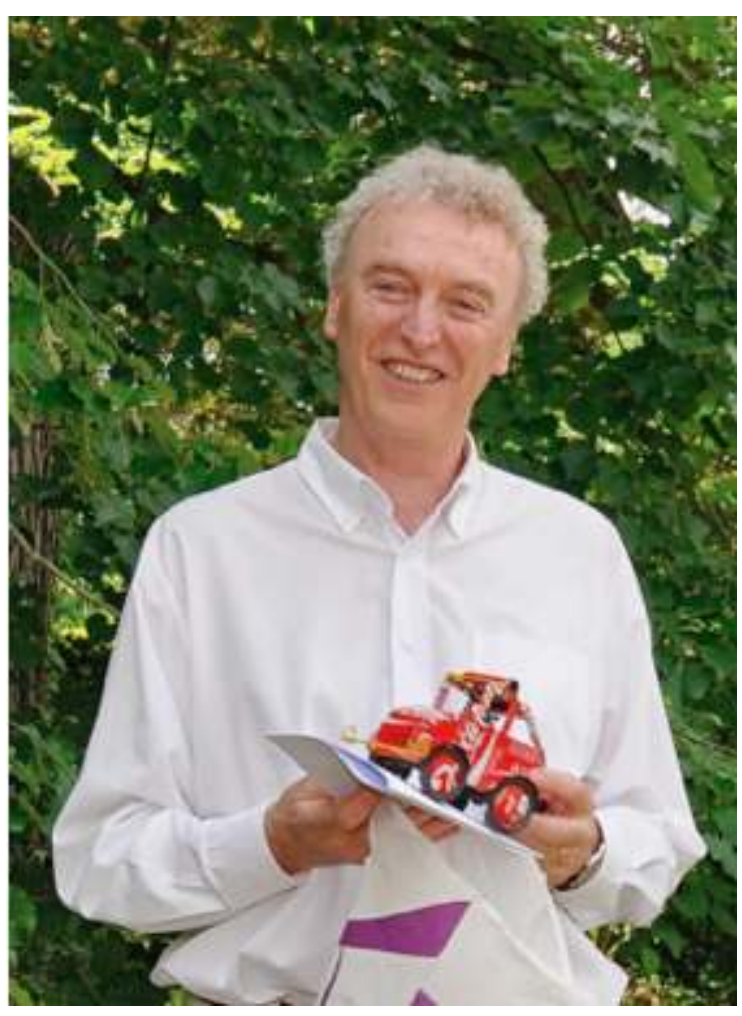

1 Le premier numéro de Mandenkan a paru il y a 33 ans. Depuis un tiers de siècle, la revue est devenue le pôle d'attraction des spécialistes en linguistique mandé et l'axe de structuration des études linguistiques mandé dans le monde. Aujourd'hui, au moment de la publication du numéro 50 de Mandenkan, je voudrais rendre hommage à son fondateur et éditeur Gérard Dumestre.

2 Si l'on compare l'état des études mandé et le niveau des connaissances des langues mandé entre aujourd'hui et il y a 33 ans, on ne peut que se rendre compte des énormes 
progrès qui ont été effectués pendant cette période. Le mérite en revient en grande partie à Gérard Dumestre. Et cela ne se limite pas à la fondation de Mandenkan. En héritier de Maurice Delafosse et Maurice Houïs, il a enseigné le bambara à l'INALCO pendant 33 ans, et ses élèves constituent la grande majorité des mandéisants européens. C'est lui qui a organisé le premier colloque Langues et linguistique mandé (Paris, 1989), devenu une tradition au fil des ans et qui a beaucoup contribué à la consolidation de la communauté mondiale des spécialistes en langues mandé. La publication en 2003 de la Grammaire fondamentale du bambara, la première description détaillée et exhaustive de cette grande langue de l'Afrique de l'Ouest, basée sur une étude méticuleuse d'un immense corpus de textes bambara, a comblé une importante lacune. Enfin, la sortie, en 2011, du monumental Dictionnaire bambara-français marque d'une pierre angulaire la lexicographie mandingue: peu nombreux sont les dictionnaires de langues africaines comparables en exhaustivité et richesse des données, et pour les langues mandé je n'en connais aucun autre.

Pendant plus de trois décennies, Mandenkan a porté la marque de la personnalité de son créateur: la passion des langues mandé, la joie de vivre, la rigueur scientifique. Cinquante numéros, c'est beaucoup, et l'on peut comprendre Gérard qui a décidé de céder sa position de coéditeur. Il reste cependant dans le Comité de rédaction où il nous aidera à assurer la qualité des articles publiés dans Mandenkan. C'est à nous tous de garder les meilleures traditions de son père fondateur. 